\title{
Midiatização e espetacularização do turismo
}

\section{Tourism mediatization and spectacularization}

\author{
Lauro Almeida de Moraes (MORAES, L. A. de) ${ }^{*} \mathrm{e}$ \\ José Manoel Gonçalves Gândara (GÂADARA, J. M. G.) ${ }^{* *}$
}

RESUMO - Este artigo baseia-se em discussão iniciada na dissertação de mestrado de um dos autores (MORAES, 2012) e apresentada em congresso por Moraes et al. (2015), a qual preconiza que a teatralidade envolve a comunicação promovida pelo turismo. Os lugares preparam-se para captar e direcionar o olhar do turista, bem como este busca determinados aspectos locais já consagrados. Neste aspecto, influi também o conteúdo divulgado pelos meios de comunicação de massa, que, comumente, também acionam o espetáculo e demandam a adaptação dos atrativos turísticos à lógica do discurso midiático. O artigo tem como objetivo, portanto, refletir acerca da midiatização e espetacularização do turismo, destacando as características elementares que denotam a presença do espetáculo nos destinos turísticos. Recorreu-se a uma revisão bibliográfica com recorte sócio-antropológico, capaz de fornecer subsídios para pesquisas empíricas. Defende-se então que a midiatização e a cultura do espetáculo contemporânea produzem novas formas de relações sociais e modelos de experiência. Desta forma, o turismo, como atividade socioeconômica indissociável da atual vida cotidiana, orientase pela lógica do "infoentretenimento".

Palavras-chave: Turismo; Cultura; Mídia; Espetáculo; Performance.

ABSTRACT - This study is based on the discussion started on the master's thesis of one of the authors (MORAES, 2012) and presented in Congress by Moraes et al. (2015), which affirms that the communication promoted by tourism is encompassed by theatricality. The places and attractions are prepared to capture and direct the tourists gaze, as well as those tourists search for certain local aspects already established. Regarding those aspects, they are also disseminated by mass media outlets that include in them the spectacle which require the adaptation of tourist attractions to the logic of media discourse. This paper aims therefore to reflect on the tourism mediatization and

\footnotetext{
* Formação: Graduação em Comunicação Social (Bacharelado) e Especialização em Políticas Públicas e Projetos Sociais pela Universidade Vale do Rio Doce (Governador Valadares, MG, Brasil), Mestrado em Cultura e Turismo pela Universidade Estadual de Santa Cruz (Ilhéus, BA, Brasil). Doutorando em Geografia na Universidade Federal do Paraná (Curitiba, PR, Brasil). Atividade profissional: Atua como jornalista há doze anos, com reportagens exibidas pela Rede Globo e publicadas pelo jornal O Estado de São Paulo. Professor em cursos de Comunicação desde 2005. Editor da Revista Geografar (ISSN: 1981089X). Endereço físico para correspondência: Universidade Federal do Paraná, Programa de PósGraduação em Geografia. Av. Cel. Francisco H dos Santos, 100 - Centro Politécnico, Edifício João José Bigarella, sl. 108. CEP 81531-980, Caixa Postal 19001 - Curitiba - Paraná (Brasil). Telefone: (41) 33613450. E-mail: lauromoraes@ufpr.br

** Formação: Graduação em Turismo pela Universidade Federal do Paraná (UFPR), Doutorado em Turismo e Desenvolvimento Sustentável (ULPGC, Las Palmas de Gran Canaria, Espanha). Atividade profissional: Professor e pesquisador do Departamento de Turismo, do Mestrado em Turismo e do Mestrado e Doutorado em Geografia da Universidade Federal do Paraná. Endereço físico para correspondência: Universidade Federal do Paraná, Departamento de Turismo. Rua Doutor Faivre, 405 $3^{\circ}$ andar - Centro. CEP: 80060-140 - Curitiba - Paraná (Brasil). E-mail: jmggandara@ yahoo.com.br
} 
spectacularization, highlighting the elementary features that denote the presence of the show in tourist destinations. As a methodological tool, a literature review under socioanthropological frame was carried out, making it able to provide support for empirical research. It is hold then, that the contemporary mediatization and spectacle culture produces new forms of social relations and experience models. In this way, the tourism, as a socio-economic activity that is inseparable from the current daily life, is guided by the logic of "infoentertainment".

Key words: Tourism; Culture; Media; Spectacle; Performing. 


\section{INTRODUÇÃO}

A comunicação promovida pelo turismo é cercada de teatralidade. Os lugares se preparam para captar e direcionar o olhar do turista, bem como este busca determinados aspectos locais já consagrados. Ou seja, há uma espécie de encenação característica que emerge nos atrativos turísticos (SILVA, 2005). E tanto turistas quanto a comunidade e o próprio destino turístico envolvem-se nesse processo de "representação" - conceito que Goffman (2002, p. 29) define como "toda atividade de um indivíduo que se passa num período caracterizado por sua presença contínua diante de um grupo particular de observadores e que tem sobre estes alguma influência".

Neste sentido, a presença da mídia também modifica a forma como um destino apresenta-se. A postura de turistas e da comunidade local muda diante das câmeras, que influenciam na performance turístico-cultural, adaptando-a a lógica do discurso midiático. Um dos mecanismos comumente acionados é o da espetacularização, que pode ser observada até mesmo no contexto informativo. Em conjunto ou separadamente, a dramatização, a diversão e a ruptura das regularidades - categorias do espetáculo definidas por Gomes (1996) - compõem a notícia sobre turismo, bem como outras narrativas da mídia destinadas a viagens.

Sob este ponto de vista, no presente artigo, propõe-se uma reflexão acerca da espetacularização no turismo, abalizado pelos trabalhos de Moraes (2012) e Moraes et al. (2015), que se orientam por uma revisão bibliográfica com recorte sócioantropológico, abrangendo bases de pesquisa nacionais e estrangeiras - ibero-americana e anglo-saxônica - principalmente nos campos do Turismo e da Comunicação. Então, quais características elementares denotariam a presença do espetáculo nos destinos turísticos e em narrativas midiáticas produzidas acerca deles? A partir da delimitação deste problema, busca-se dar vazão e amplificar os referidos estudos, discutindo-se, inicialmente, sobre o papel das performances tanto para a atratividade turística quanto para a comunicação estabelecida entre visitantes e visitados. E em seguida, reflete-se acerca da adaptação do turismo à lógica espetacular e midiática, bem como a extensão atingida pela cultura do espetáculo no contexto vigente. 


\section{PERFORMANCES TURÍSTICAS: O ESPETÁCULO VAI COMEÇAR}

Os turistas, geralmente, assumem um afastamento com seus locais de origem durante as viagens. Uma ruptura limitada e temporária que permite que seus sentidos se abram a novos estímulos. Desta forma, até mesmo práticas que seriam socialmente reprimidas na região de onde vieram tornam-se cabíveis pelo distanciamento do seu cotidiano. Segundo Urry (2001, p. 27), tal postura denota que "existe uma licença para um comportamento permissivo, alegre, 'não sério' e o encorajamento de um 'communitas ${ }^{1}$ relativamente livre de restrições, bem como uma proximidade social'.

Esse comportamento do turista pode ser explicado ainda por meio de uma categoria estabelecida pelo precursor dos estudos da performance Richard Schechner (1995). A partir da ideia de transportation, o autor introduz a noção de que os atores sociais são levados a assumir papéis distintos daqueles adotados rotineiramente. Ao tratar deste conceito, Silva (2005) desenvolve uma perspectiva complementar ao pensamento de Urry (2001). De acordo com Silva (2005, p. 50):

[...] durante uma performance também a "audiência" é "transportada", pois o ator social, na posição de platéia, é levado a assumir outros papéis diferentes dos que habitualmente desempenha nas interações sociais da vida cotidiana [...]; ele poderá se sentir mais "livre" para explorar com ousadia o repertório variado de papéis sociais e, assim, expressar, sem receio, as suas emoções, chorar, gargalhar, agir com irreverência, gritando, assoviando alto, etc.

Os atores sociais responsáveis pela apresentação dos destinos turísticos e seus atrativos, por sua vez, participam da performance como se preparassem um vídeo, editando-o, reconstruindo-o, mudando cenários, o elenco, independentemente de seus fatores causais. A montagem dessa sequência e sua apresentação é o que Schechner (1995) chama de "restauração do comportamento", o que torna possível, por exemplo, o resgate de práticas e atividades culturais esquecidas, ou mesmo desaparecidas, e sua apropriação para fins turísticos.

\footnotetext{
${ }^{1}$ Categoria estabelecida por Turner (1974) que representa a identificação que une os indivíduos num estágio liminar, motivados por crenças, valores ou ideais coletivos, configurando uma "antiestrutura". Com base em Turner (1974), Silva (2005, p. 39) delineia esta "antiestrutura" como "um modelo alternativo e espontâneo de organização social que emerge momentaneamente nos interstícios da sociedade".
} 
[...] esses tipos de "comportamento restaurado" (restauração de eventos performáticos) possibilitam, também, compreender que as performances são atividades culturais criativamente reproduzidas ao longo do tempo, num processo que tende a envolver interesses diversos e sugerir pluralidade de significados. Quero com isso dizer, parafraseando Schechner, que o "comportamento restaurado" é "comportamento simbólico" e, enquanto tal, também o é potencialmente polissêmico. Portanto, é sob esse ponto de vista que a noção de "comportamento restaurado" torna-se instigante para se pensar sobre os grupos de congadas que, tanto no interior de Minas Gerais quanto nos arredores de São Paulo, continuam a ser mantidos desde sempre ou recriados em nome da "tradição", espontaneamente ou através do incentivo de folcloristas, secretarias municipais de culturas e artistas [...] (SILVA, 2005, p. 57).

Como se nota, existe uma carga performática e, por vezes, dramática, genuína ou reconstruída, em torno dos atrativos turístico-culturais. Nesse sentido, Wainberg (2003, p. 35-36) compara turismo e cinema, afirmando que ambos produzem um efeito "mágico", "hipnotizante" no público. Desta forma, "como ação cênica que é, o turismo demanda palco e luzes, cenas, mesmo que elaboradas pela mão do ser humano", aproximando-se do espetáculo. Particularmente, uma "geografia do espetáculo".

O autor da obra A sociedade do espetáculo, Debord (1997, p. 17) afirma que "toda a vida nas sociedades nas quais reinam as modernas condições de produção se apresenta como uma imensa acumulação de espetáculos. Tudo que era vivido diretamente tornou-se uma representação" E de acordo com Connell (2005, p. 764) 2, “à medida que as experiências do turismo têm sempre focado no espetáculo, a descrição de Debord $(1983)^{3}[\ldots]$ torna-se cada vez mais relevante, assim como os produtos turísticos estão cada vez mais diversificados e baseados no consumo".

Para Connell (2005, p. 764), as experiências do pós-turismo privilegiam o "simulacro", ou seja, “[...] deram origem à emergência do conceito de hiperrealidade no

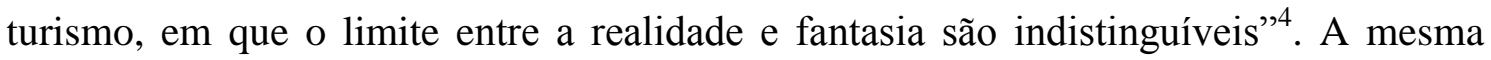
autora comenta que conteúdos televisivos, como Balamory - programa infantil da BBC, gravado numa ilha da Escócia, que deu origem a um tipo de turismo na Europa denominado pela autora de toddler tourism (turismo infantil) - e filmes como Coração

\footnotetext{
${ }^{2}$ Although tourism experiences have always focused on the spectacle, Debord's (1983) description [...] is ever more relevant as tourism products become increasingly diverse and consumption-based.

${ }^{3}$ Referência da autora à obra A sociedade do espetáculo em língua inglesa.

${ }^{4}[\ldots]$ have given rise to the emergence of the hyper-reality concept in tourism where the boundary between reality and fantasy is indistinguishable.
} 
Valente (Escócia) e Crocodilo Dundee (Austrália) são alguns exemplos que contribuíram para aumentar o fluxo turístico nessas regiões desta forma.

Do ponto de vista de Debord (1997), há uma relação social, um compartilhamento entre as pessoas para a recepção do espetáculo, e esta relação é mediada por imagens. É nesse sentido que Carvalho (2007, p. 289) estabelece uma crítica ao que chama de "fetichismo da mercadoria-paisagem", em referência ao expressivo "gosto imagético da imprensa, espectadores e leitores" nas reportagens sobre turismo.

Os "paraísos turísticos" difundidos pela mídia como fantasias realizáveis são consumidos em modelos padronizados de estrutura com perdas na paisagem e na cultura originais, transformados em cenários artificiais onde se desenrolam espetáculos devidamente ensaiados para cativar o turista (CARVALHO, 2007, p. 294).

Este conceito encaixa-se, sobretudo, no "turismo de enclave", em que os espaços são especialmente concebidos, programados e organizados para visitação turística. Camargo (2009, p. 74) cita, nesse sentido, as hospedagens em resorts e viagens em cruzeiros, em que o turista instala-se com "tudo incluído". Segundo Wainberg (2003, p. 37), "no enclave, predomina a vigilância. Tudo que ali se passa é calculado", como num parque temático, tal qual a Disneylândia, que, de um ponto de vista mais ortodoxo, "dá a ilusão de um mundo real, um mundo externo" (BAUDRILLARD, 2004, p. 20).

O fato é que os espaços turísticos, num contexto geral, passam por transformações cênicas, cada um com um grau maior ou menor de planejamento e articulação, como mostram os estudos de Graburn (2008) e Brito (2008). E, com efeito, a presença da mídia também modifica a forma como um destino se apresenta. A postura de turistas e da comunidade local tende a mudar diante de um jornalista, por exemplo, gerando um controle ainda maior do espaço turístico, mesmo naqueles considerados espontâneos, heterogêneos, em que o grau de manipulação do cenário é menor e, por isso, são dispostos de uma forma mais próxima do que se considera natural, autêntico (BUCHMANN; MOORE; FISHER, 2010). 


\title{
3 O TURISMO E SUA ADAPTAÇÃO À LÓGICA ESPETACULAR E MIDIÁTICA
}

Os empreendedores, gestores públicos e demais envolvidos com a atividade turística querem, obviamente, mostrar um cenário perfeito, pois é assim que desejam ser apresentados ao grande público (WOLTON, 1997). A ideia é remover "os elementos caóticos" da realidade (ROJEK, 1995, p. 62), fazendo com que as câmeras sejam direcionadas apenas para aquilo que se considera positivo. Esconde-se, então, ao máximo do jornalista o backstage ${ }^{5}$, os camarins, a privacidade dos atores, como diria Goffman (2002). Nesse aspecto, vale ressaltar as considerações do autor acerca do controle da informação em uma representação:

\begin{abstract}
Um objetivo de qualquer equipe é manter a definição da situação que sua representação alimenta. Isto implicará que se acentue a comunicação de alguns fatos e se diminua a comunicação de outros. Dada a fragilidade e a necessária coerência expressiva da realidade que é dramatizada por uma representação, há geralmente fatos que, caso expostos à atenção durante uma representação, poderão desacreditar, romper ou tornar inútil a impressão que ela estimula. Diz-se que estes fatos fornecem "informação destrutiva". Um problema básico de muitas representações, portanto, é o do controle da informação (GOFFMAN, 2002, p. 132).
\end{abstract}

A partir destas considerações, compreende-se, então, que a imprensa exerce influência sobre a performance turístico-cultural, adaptando-a à lógica do discurso midiático. E um dos mecanismos comumente acionados é o da espetacularização, que, a despeito de ser mais comumente relacionada aos apelos do merchandising, também pode ser observada no contexto da informação jornalística, conforme destaca Gomes (1996). Nesse sentido, segundo o autor, a publicidade aparece como o meio mais espetacular - tanto no sentido estrito quanto debordiano da palavra - e eficaz de racionalização do sistema produtivo, tornando-se o ponto-chave da comunicação de massa. Ele defende que todo o conteúdo dos veículos de comunicação gira em torno da lógica publicitária, que é a "lógica do entretenimento".

[...] todos os outros sistemas (a informação, a 'cultura' em sentido estrito, a ficção, etc.) apresentam-se nos meios de comunicação, particularmente nos meios privados de comunicação, como intervalos, mais ou menos longos, para a publicidade. [...] mesmo os jornais impressos sobrevivem da

\footnotetext{
${ }^{5}$ Fundo do palco, isto é, os bastidores.
} 
publicidade e não da venda de exemplares. Praticamente tudo se torna, então, entretenimento, distração, diversão, que nos segura o suficiente (e quanto mais melhor) para que a vitrine massmediática (grifo nosso) entre em ação. E quando a vitrine publicitária é acionada, ainda assim nos entretemos, porque tudo é preparado para nos agradar, divertir (GOMES, 1996, p. 33).

Não obstante, esta espécie de ethos social $^{6}$, calcado na estética e no consumo dos valores intrínsecos à propaganda, não pode ser reduzida, simplesmente, ao âmbito dos mass media ${ }^{7}$. A rigor, este novo ambiente sociocultural também parte dos esforços de um sistema produtivo que precisou racionalizar o processo de produção, a fim de introduzir o capitalismo em uma nova fase, em que o mercado fosse dominado e não o contrário. "Era preciso substituir a necessidade pelo desejo, a carência pela sedução" (GOMES, 1996, p. 32). O turismo, atualmente, está entre os desejos de consumo dos indivíduos, aproveitando-se, igualmente a outras esferas sociais, das estratégias midiáticas de sedução e, ao mesmo tempo, sendo o próprio turismo adotado como mecanismo de sedução.

Em Veneza, pode-se comprar um cartão postal que faz ao mesmo tempo propaganda da cidade e de um truste norte-americano. Ele mostra a Praça de São Marco vazia, ocupada apenas pelo notório exército de pombos. Estes apresentam-se de forma organizada: em caracteres gigantescos, eles formam a palavra "Coca-Cola". Os caracteres são aqueles do design da marca 'legalmente registrada'. O gerente publicitário produziu a configuração dessa foto fazendo que várias pessoas contratadas espalhassem comida para os pombos de modo a formar a logomarca. Os pombos não se colocaram ali para formar a logomarca, mas para saciar a sua fome. A comida não foi espalhada para alimentar os pombos, mas para fazê-los trabalhar como figurantes, ao se dirigirem a ela. $\mathrm{O}$ arranjo é absolutamente estranho e externo aos pombos. Ao incorporarem a comida, eles são subordinados ao capital e incorporados por ele. A foto - um triunfo da técnica publicitária capitalista - mostra simbolicamente um aspecto fundamental do capitalismo (HAUG, 1997, p. 167).

Seguindo essa linha de raciocínio, em que a publicidade serve de forma conveniente e eficaz ao sistema produtivo, descrever-se-á, então, as três categorias sobre as quais se assenta a espetacularização midiática: ruptura das regularidades, diversão e dramatização (GOMES, 1996). A respeito da ruptura das regularidades, do ponto de

\footnotetext{
${ }^{6}$ Síntese motivadora de ideias e costumes no seio social, apreendida por meio de um comportamento global e que agrega amplo e difuso conjunto de representações sociais. Como defende Bourdieu (1990), há uma estreita relação entre os conceitos de ethos e habitus.

7 Sistemas organizados de produção, difusão e recepção de informação (CLOUTIER, 1975). Termo comumente utilizado como sinônimo de meios de comunicação, mídia.
} 
vista psicológico, os indivíduos tendem a voltar a atenção para objetos e eventos que introduzam um ritmo inesperado ou conexão incomum no cotidiano. Este é ponto-chave da famosa definição de notícia atribuída a Amus Cummings, então editor do New York Sun: "Se um cachorro morde um homem, não é notícia; mas se um homem morde um cachorro, aí, então, é notícia, e sensacional” (PENA, 2005, p. 90). O espetáculo remete, portanto, ao "surpreendente", ao "excepcional", ao "extraordinário" (RUBIM, 2005, p. 13).

Segundo Gomes (1996), mesmo que seja essencial perceber a homogeneidade dos ritmos e relações para a organização da vida social, o inédito, o diferente, a transgressão, o espetacular, a novidade, o choque, a contenda, a mudança capturam a memória dos destinatários das mensagens. Nesse quesito, cabe ressalvar que as “experiências diferentes" estão justamente no cerne das discussões sobre o turismo pósindustrial (RUSCHMANN, 1994, p. 12). E mesmo autores clássicos já consideravam o componente da distinção como característica motivadora do turismo, definido por Wahab (1977, p. 83) como "fuga, gosto pela cultura e modo de vida de outros povos para compreender a razão da diferença entre os seres humanos”.

Como uma espécie de subsistema da ruptura das regularidades, situa-se a diversão, posto que "divertir-se é, literalmente, voltar-se do quotidiano para o novo, o diferente, o irregular, o extraordinário. Pelo acionamento da diversão, que envolve prazer, a captura da atenção e da memória certamente torna-se mais fácil e, possivelmente, mais eficaz" (GOMES, 1996, p. 37). Nesse sentido, o autor afirma que o princípio fundamental do artifício do divertimento é invalidar, mesmo que em parte, o real.

Esse tipo de exposição tanto pode gerar frutos positivos quanto negativos. O aumento exagerado da demanda gera novos desafios para a gestão local e influencia o perfil do visitante (CONNELL, 2005). Turistas que se identificam com lugares tranquilos, possivelmente, os evitarão se passarem a receber fluxos massivos. Além das questões mercadológicas, a sustentabilidade da atividade turística depende, portanto, de uma harmonia entre fatores econômicos, sociais, ambientais e culturais. (KRIPPENDORF, 2000; BENI, 2003).

No que se refere à dramatização, conforme aventado anteriormente, a encenação está no cerne do espetáculo. As narrativas e personagens espetaculares, de alguma 
forma, são teatralizados a fim de tocar os sentimentos, provocar a emoção, atrair a atenção (GOMES, 1996). O "maravilhamento" com o evento espetacular, conforme classifica Rubim (2005, p. 14), depende da exacerbação da "dramaticidade de sua trama e de seu enredo, através de apelos e dispositivos plástico-estéticos". Segundo o autor,

\begin{abstract}
A plasticidade visual, componente essencial, a sonoridade tornam-se vitais: os movimentos, os gestos, os corpos, as expressões corporais e faciais, o vestuário, os cenários, a sonoridade, as palavras, as pronúncias, as performances; enfim, todo esse conjunto de elementos e outros não enunciados têm relevante incidência na atração da atenção, na realização do caráter público e na produção das simbologias e dos sentidos pretendidos com o espetáculo. (RUBIM, 2005, p. 14).
\end{abstract}

As considerações de Rubim (2005) desvencilham-se do olhar neomarxista radical de Debord (1997) acerca do espetáculo e vão ao encontro das novas tendências socioeconômicas da atualidade, cuja evolução aponta para a transição da economia de serviços para a economia da experiência (PINE II; GILMORE, 1999). Como sustentam Morgan, Elbe e Curiel (2009, p. 203) ${ }^{8}$, este processo implica compreender os clientes como participantes ativos, em vez de consumidores passivos, pois o "escapismo hedonista muitas vezes não é um fïm em si, mas um meio de satisfazer as aspirações mais profundas".

Os reflexos disso para o turismo levam, justamente, a incutir marcas emocionais, surpresas, histórias, sonhos, fantasias, vivências extraordinárias nos seus produtos. (GÂNDARA et al., 2012; VALDUGA et al., 2014; PULIDO-FERNÁNDEZ; NAVARRO HERMOSO, 2014; SANTOS; GUZMÁN, 2014). Desta forma, busca-se envolver e encantar o proksumer turístico ${ }^{9}$ (TORRES MONTESINOS; GARCÍA SUÁREZ; PULIDO-FERNÁNDEZ, 2013). Como consequência, “[...] tornou-se implícito no turismo contemporâneo que as atividades mais 'corporais' devem acontecer em cenários espetaculares" (REIS, 2010, p. 309).

Todavia, essa espetacularização pode ser vista por outro ângulo que não o da pura e simples “[...] sedução das aparências, a embriaguês visual, a velocidade, a beleza

\footnotetext{
${ }^{8}$ Hedonic escapism is often not an end in itself but a means of fulfilling deeper aspirations.

9 Tipologia de consumidor potencializada pela sociedade em rede, caracterizada por uma atitude ativa, colaborativa e co-criadora em relação à configuração dos produtos e às experiências de consumo. Busca compartilhar suas vivências através das redes sociais, recomendar ou contraindicar, estabelecendo um novo contexto para as estratégias de planejamento e marketing aplicadas a destinos turísticos.
} 
a todo custo, o prazer imediato, história e personagens que podem ser rapidamente identificados, produtos que solicitam uma interpretação mínima" (GOMES, 1996, p. 38). Pelo contrário, o espetáculo, outrossim, tem seu lado positivo e deve ser compreendido como inerente e imprescindível a todas sociedades humanas.

\begin{abstract}
$\mathrm{Na}$ contramão das concepções debordianas, hoje parece assentado teoricamente que não existe a possibilidade de uma relação direta, não mediada, com a realidade; que a representação não só faz parte da realidade, como aparece como dispositivo imprescindível de sua construção social e que o estatuto de realidade da representação nada fica a dever àquele atribuído ao restante da realidade, aliás, só possibilitada através do recurso às mediações (RUBIM, 2002, p. 5).
\end{abstract}

O espetáculo, então, não é uma obra da mídia, do poder capitalista ou qualquer outro agente contemporâneo, apesar de acionado por muitos deles, mas uma "invenção" da raça humana. Rubim (2002) reconhece que as mais diversas variações do espetáculo têm sido vivenciadas e contempladas, em grande parte, através dos veículos de comunicação, visto que o processo de midiatização, crescente e pujante na contemporaneidade, determinou o ajustamento dos mais variados discursos à lógica midiática. Todavia, a midiatização não pode ser confundida com a espetacularização.

A midiatização é um fenômeno recente, cujo desenvolvimento se deu no mesmo ritmo acelerado dos avanços tecnológicos das últimas quatro décadas, garantindo que a mídia figure como espaço privilegiado de visibilidade social e legitimação de discursos (RODRIGUES, 1994; HJARVARD, 2012). Ademais, é nítida a capacidade dos meios de comunicação de encurtar distâncias, estabelecendo vivências planetárias e em tempo real (MCLUHAN, 1971; LÉVY, 2001), que, necessariamente, não precisam ser espetaculares.

O espetáculo, por sua vez, é o movimento que desencadeia a representação do real e sua reconfiguração numa dinâmica, em geral, de entretenimento, diversão e ruptura com a ordem cotidiana. Tal operação não só possui um caráter público, como também é imanente às sociedades humanas. Ocorre, no entanto, que a conexão entre mídia e espetáculo chegou a um estágio de imbricação que a construção e a disseminação do espetacular já não podem ser realizadas sem a presença dos aparatos midiáticos, mas somente se estes atuarem em conjunto com outros atores sociais produtores de espetáculos. Segundo Rubim (2002, p. 18), este sim é um novo 
fenômeno, que potencializa a abrangência do espetáculo e cria "gigantescas máquinas midiáticas de espetacularização", pois os meios de comunicação adquiriram a capacidade de canalizar em si todas as formas de espetáculo.

\title{
4 MUITO ALÉM DO TURISMO: UMA CULTURA DO ESPETÁCULO
}

No contexto traçado até aqui, é compreensível que a ultramidiatização oportunize a superespetacularização. Tanto que Kellner (2003, p. 7) defende a ideia de uma "cultura do espetáculo", conforme abaixo:

\begin{abstract}
A partir da tradição do espetáculo, as formas contemporâneas de entretenimento, desde a televisão até o palco, incorporam a cultura do espetáculo a seus empreendimentos, transformando o filme, a televisão, a música, o drama e outras áreas da cultura, produzindo novas formas de cultura espetaculares tais como o ciberespaço, a multimídia e a realidade virtual.
\end{abstract}

Considera-se ficar claro que há um vasto campo para a espetacularização, abrangendo as mais diversas esferas sociais: espetáculos da TV, do cinema, sériesespetáculo, espetáculos do esporte, teatrais, musicais, eróticos, da moda, dos jogos de computador, da gastronomia etc. "O espetáculo da mídia está invadindo todos os campos da experiência, desde a economia e a cultura até a vida cotidiana [...]" (KELLNER, 2003, p. 11). Sendo assim, a lógica do infoentretenimento também compõe a conformação dos produtos turísticos, desenvolvendo de alguma forma a diversão, a teatralização/dramatização e a ruptura das regularidades. Uma tendência que se conecta harmonicamente com a economia da experiência, centrada "nas experiências e nas histórias, por meio de um conjunto de eventos memoráveis que alguém encena para cativar, entreter ou fascinar o cliente" (GUZMÁN; VIEIRA JÚNIOR; SANTOS, 2011, p. 101).

Evidentemente, não só o espetáculo, tampouco somente o que se opera no campo do turismo, possui caráter dramático e teatral. A vida diária, com seus ritos e rituais cotidianos, do mesmo modo, tem formas particulares de encenação e dramaticidade (GOFFMAN, 2002). Quanto à ruptura com a ordem cotidiana - o 
surpreendente, o excepcional - apesar de, em geral, ser produzida propositalmente pode ocorrer de maneira imprevista em algumas ocasiões.

\begin{abstract}
A ruptura da vida ordinária propicia não uma situação de caos, de ausência completa de normas sociais, mas a suspensão temporária da vigência das regras cotidianas. Um outro conjunto de normas produtivas, agora condizentes com o momento extraordinário, impõe-se como necessidade. Mais que isso, a ruptura com o cotidiano e seu saber de senso comum faz aflorar a exigência de um saber e um conjunto especializado de técnicas para lidar com a construção social do momento excepcional (RUBIM, 2005, p. $15)$.
\end{abstract}

Rubim (2005) aceita que a sociedade contemporânea, ambientada pela mídia, possui uma pujante tendência espetacular; que a espetacularização ganha importância neste mundo globalizado, em que existem várias e difusas concepções e interesses, cada um querendo mais visibilidade, um lugar ao sol; e que face as desiguais relações capitalistas, o espetáculo beneficia mais as elites. Todavia, não abre mão da perspectiva de que há espaço para a pluralidade de pensamento e a reflexão, visto que esta nova sociabilidade espetacular tem se mostrado surpreendente e incerta. Ainda mais considerando que a atual cultura do espetáculo circula pelo ciberespaço em amplas redes multimídia e de "infoentretenimento". Segundo Kellner (2003, p. 14):

[...] estamos entrando numa nova cultura do espetáculo que constitui uma nova configuração da economia, sociedade, política e vida cotidiana, que envolve novas formas de cultura e de relações sociais e novos modelos de experiência. Isso está produzindo uma nova cultura do espetáculo com o surgimento de diversos espetáculos, de megaespetáculos e de espetáculos interativos.

O espetacular configura-se, então, como construção social e discursiva. E nesse novo contexto, as diversas esferas sociais - Política, Religião, Economia, Direito, Ciência, Cultura, Turismo etc. - coparticipam da existência e realização do espetáculo, visto que há uma predisposição geral, cada vez maior, a atrair a atenção para si. E se a ideia é ganhar visibilidade e, ao mesmo tempo, credibilidade, isto é possível, em primeiro lugar e de modo mais eficaz, por meio do jornalismo. 


\section{CONSIDERAÇÕES FINAIS}

O espetáculo está integrado ao turismo no contexto vigente, assim como ampliou sua presença na economia, na política e na vida cotidiana, instituindo novas formas de relações sociais e modelos de experiência. Vale, portanto, retomar o problema delimitado neste artigo: quais características elementares denotam a presença do espetáculo nos destinos turísticos e em narrativas midiáticas produzidas acerca deles? Fundamentalmente, nota-se que o turismo contemporâneo orienta-se por uma lógica alinhada ao "infoentretenimento", cuja dinâmica envolve dramatização/teatralização, diversão e ruptura das regularidades. Isto é, a atividade turística também produz espetáculos de diversas matizes, formas e abrangência - do micro ao megaespectáculo, do monológico ao interativo, do presencial/corpóreo ao midiatizado.

Com efeito, o turismo midiatizado e/ou espetacularizado aproveita-se dos mesmos mecanismos de sedução adotados por outras esferas sociais. Desta forma, busca incutir surpresas, fantasias, histórias, marcas emocionais e vivências extraordinárias nos produtos turísticos. Contudo, não foi a mídia que inventou esta "fórmula". Este é o cerne do turismo de experiência, particularmente o desenvolvido pela vertente alinhada ao marketing, que se diferencia das formulações propostas pela ala filosófica. Isso implica que o espetáculo pode atuar de forma positiva, no sentido de melhorar o produto turístico, envolver o turista. Desta forma, as teorias em torno da midiatização e da espetacularização revelam-se aportes relevantes para estudos sobre qualidade, sustentabilidade, planejamento e gestão de destinos turísticos, bem como para a crítica social da conjugação entre mídia, espetáculo e turismo.

A bem da verdade, a cultura do espetáculo e a midiatização conjugam-se, de modo profícuo, na criação da "imagem perfeita" no turismo, que privilegia a estética do belo, do diferente, do surpreendente, do excepcional, do extraordinário, enfim, do espetacular. Ao mesmo tempo, a imagem espetacular dos atrativos turísticos atrai audiência. Nesse sentido, o próprio apelo mercadológico desvela o caráter paradoxal do espetáculo, que tanto pode favorecer a dimensão da sustentabilidade econômica, ambiental e social do turismo quanto reduzir as experiências turísticas aos seus aspectos espetaculares e passíveis de midiatização. Todavia, o significado e valor para o turista de recursos naturais, patrimônios materiais e imateriais, equipamentos e serviços 
turísticos dependem mais do que verossimilhança. Necessitam ser efetivamente ofertados nas condições divulgadas pelos meios de comunicação. Do contrário, perderse-ia o encanto da vivência espetacular em sua concretude e da própria atratividade turística em face da incoerência entre a experiência e um "turismo imaginário", puramente imagético.

\section{REFERÊNCIAS}

BAUDRILLARD, J. Telemorfose. Rio de Janeiro: Mauad, 2004.

BENI, M. C. Globalização do turismo: megatendências do setor e a realidade brasileira. 2. ed. São Paulo: Aleph, 2003.

BOURDIEU, P. Sociología y cultura. México: Grijalbo, 1990.

BRITO, B. R. O turista e o viajante: contributos para a conceptualização do turismo alternativo e responsável. In: CONGRESSO PORTUGUÊS DE SOCIOLOGIA, 4., 2008, Lisboa. Anais... Lisboa: Universidade Nova de Lisboa, 2008. p. 1-17.

BUCHMANN, A.; MOORE, K.; FISHER, D. Experiencing film tourism: authenticity \& fellowship. Annals of Tourism Research, v. 37, n. 1, p. 229-248, 2010.

CAMARGO, P. Os impactos do turismo cultural. In: CAMARGO, P.; CRUZ, G. Turismo cultural: estratégias, sustentabilidade e tendências. Ilhéus: Editus, p. 69-88, 2009.

CARVALHO, A. L. P. de. O turismo como produto da indústria cultural nas enunciações da mídia. In: PAIVA, C. C. de; BARRETO, E. B.; BARRETO, V. S. (Orgs.). Mídia \& Culturalidades: análises de produtos, fazeres e interações. João Pessoa: Universitária, p. 277-297, 2007.

CLOUTIER, J. A era de EMEREC ou a comunicação audio-scripto-visual na hora dos self-media. Lisboa: Instituto de Tecnologia Educativa, 1975.

CONNELL, J. Toddlers, tourism and Tobermory: Destination marketing issues and television-induced tourism. Tourism Management, Amsterdam, v. 26, n. 5, p. 763776, out. 2005.

DEBORD, G. A sociedade do espetáculo. Rio de Janeiro: Contraponto, 1997.

GÂNDARA，J. M.; MENDES，J.; MOITAL，M.; RIBEIRO，F. N.; SOUZA， I.; GOULART, L. A. Planificación estratégica de um circuito turístico histórico cultural experiencial - Itabuna - Bahia, Brasil. Estudios y Perspectivas en Turismo, Buenos Aires, v. 21, n. 1, p. 225-248, fev. 2012. 
GOFFMAN, E. A representação do eu na vida cotidiana. 10. ed. Petrópolis: Vozes, 2002.

GOMES, W. S. Duas premissas para a compreensão da política espetáculo. In: NETO, A. F.; PINTO, M. J. (Orgs.). O indivíduo e as mídias. Rio de Janeiro: Diadorim, 1996, p. $30-46$.

GRABURN, N. Reconstruindo a tradição: turismo e modernidade na China e no Japão. Revista Brasileira de Ciências Sociais, São Paulo, v. 23, n. 68, p. 11-21, out. 2008.

GUZMÁN, S. J. M; VIEIRA JÚNIOR, A.; SANTOS, I. J. Turismo de experiência: uma proposta para o atual modelo turístico em Itacaré - Bahia. Cultur, Ilhéus, n. 1, p. 98113, jan. 2011.

HAUG, W. F. Crítica da estética da mercadoria. São Paulo: Unesp, 1997.

HJARVARD, S. Midiatização: teorizando a mídia como agente de mudança social e cultural. Matrizes, 2013, p. 53-91.

KELLNER, D. A cultura da mídia e o triunfo do espetáculo. Líbero, São Paulo, v. 6, n. 11, p. 4-15, jun. 2003.

KRIPPENDORF, J. Sociologia do Turismo: para uma nova compreensão do lazer e das viagens. São Paulo: Aleph, 2000.

LÉVY, P. Conexão Planetária. Rio de Janeiro: Editora 34, 2001.

McLUHAN, M. Os meios de comunicação como extensões do homem. 3. ed. São Paulo: Cultrix, 1971.

MORAES, L. A. de. "Tô de folga": a construção da notícia sobre turismo no Jornal Hoje. Dissertação (Mestrado em Cultura e Turismo), Ilhéus: Universidade Estadual de Santa Cruz, 2012.

MORAES, L. A.; GOMES, D. C.; PINTO, F. D. A.; OLIVEIRA; L. G. C.; MONTEIRO; D. R. Espaços midiatizados e espetacularizados: a reconfiguração do território a partir do turismo. CONGRESSO DE CIÊNCIAS DA COMUNICAÇÃ̃O NA REGIÃO SUDESTE, 20, Anais... São Paulo: Intercom, 2015, p. 1-14.

MORGAN, M.; ELBE, J.; CURIEL, J. Has the Experience Economy Arrived? The Views of Destination Managers in Three Visitor-dependent Areas. International Journal of Tourism Research, Bournemouth, v. 11, n. 2, p. 201-216, abr. 2009.

PENA, F. Teoria do jornalismo. São Paulo: Contexto, 2005.

PINE II, J.; GILMORE, J. The experience economy. Boston: HBS Press, 1999. 
PULIDO-FERNÁNDEZ, J. I. ; NAVARRO HERMOSO, Ú. Identificación de ítems para medir las experiencias. Cultur, Ilhéus, n. 1, p. 4-34, fev. 2014.

REIS, A. C. Sentindo na pele: corpos em movimento na experiência turística na natureza. In: PANOSSO NETTO, A.; GAETA, C. (Orgs.). Turismo de experiência. São Paulo: Senac, 2010, p. 297-314.

RODRIGUES, A. D. Comunicação e cultura: a experiência cultural na era da informação. Lisboa: Editorial Presença, 1994.

ROJEK, C. Decentring leisure: rethink leisure theory. Londres: SAGE, 1995.

RUBIM, A. A. C. Espetáculo, política e mídia, 2002. Disponível em: <http://bocc.ubi.pt/pag/rubim-antonio-espetaculo-politica.pdf>. Acesso em: 10/08/2004.

RUBIM, A. A. C. Espetáculo. In: RUBIM, A. A. C. Cultura e atualidade. Salvador: EDUFBA, 2005, p.11-28.

RUSCHMANN, D. O planejamento do turismo e a proteção do meio ambiente. São Paulo: Edusp, 1994.

SANTOS, I. J.; GUZMÁN, S. J. M. Turismo de experiência: uma alternativa socioeconômica para Itacaré (BA)?. Caderno Virtual de Turismo, Rio de Janeiro, v. 14, n. 2, p. 117-132, ago. 2014.

SCHECHNER, R. Restauração do comportamento. In: BARBA, E.; SAVARESE, Nicola. A arte secreta do ator: dicionário de antropologia teatral. Campinas: Hucitec, 1995, p. 205-210.

SILVA, R. A. Entre "artes" e "ciências": a noção de performance e drama no campo das ciências sociais. Horizontes Antropológicos, Porto Alegre, v. 11, n. 24, p. 35-65, dez. 2005.

TORRES MONTESINOS, M.; GARCÍA SUÁREZ, J. A.; PULIDO-FERNÁNDEZ, J. I. Cambio de paradigma en el marketing de destinos turísticos: el Plan CMA Experience. Cultur, Ilhéus, n. 2, p. 4-32, jun. 2013.

TURNER, V. O processo ritual. Petrópolis: Vozes, 1974.

URRY, J. O olhar do turista: lazer e viagens nas sociedades contemporâneas. 3. ed. São Paulo: Nobel, 2001.

VALDUGA, V.; BIZINELLI, C.; GÂNDARA, J. M.; MANOSSO, F. C. A cachaça e o turismo no território do vinho: Rio Grande do Sul (Brasil). Revista Hospitalidade, São Paulo, v. 11, n. 2, dez. 2014, p. 195 - 222.

WAHAB, S.-E. A. Introdução à administração do turismo. São Paulo: Pioneira, 1977. 
WAINBERG, J. Turismo e Comunicação: a indústria da diferença. São Paulo: Contexto, 2003.

WOLTON, D. Elogio do grande público: uma teoria crítica da televisão. Campinas: Ática, 1997.

Recebido em: 23-03-2015.

Aprovado em: 22-04-2015. 